\title{
Khatyrka, a new CV3 find from the Koryak Mountains, Eastern Russia
}

\author{
Glenn J. MACPHERSON ${ }^{*}$, Christopher L. ANDRONICOS ${ }^{2}$, Luca BINDI ${ }^{3}$, Vadim V. DISTLER ${ }^{4}$, \\ Michael P. EDDY ${ }^{5}$, John M. EILER ${ }^{6}$, Yunbin GUAN ${ }^{6}$, Lincoln S. HOLLISTER ${ }^{7}$, \\ Alexander KOSTIN ${ }^{8}$, Valery KRYACHKO ${ }^{4}$, William M. STEINHARDT ${ }^{9}$, \\ Marina YUDOVSKAYA ${ }^{4}$, and Paul J. STEINHARDT ${ }^{10}$ \\ ${ }^{1}$ Department of Mineral Sciences, National Museum of Natural History, Smithsonian Institution, \\ Washington, District of Columbia 20560, USA \\ ${ }^{2}$ Department of Earth \& Atmospheric Sciences, Purdue University, 550 Stadium Mall Drive, \\ West Lafayette, Indiana 47907, USA \\ ${ }^{3}$ Dipartimento di Scienze della Terra, Università di Firenze, Via La Pira 4, I-50121 Florence, Italy \\ ${ }^{4}$ Russian Academy of Sciences, Petrography, Mineralogy, and Geochemistry (IGEM), Institute of Geology \\ of Ore Deposits, Staromonetny per. 35, Moscow 119017, Russia \\ ${ }^{5}$ Department of Earth, Atmospheric, and Planetary Sciences, Massachusetts Institute of Technology, \\ Cambridge, Massachusetts 02139, USA \\ ${ }^{6}$ Division of Geological and Planetary Sciences, California Institute of Technology, Pasadena, California 91125, USA \\ ${ }^{7}$ Department of Geosciences, Princeton University, Guyot Hall, Princeton, New Jersey 08544, USA \\ ${ }^{8}$ Geoscience Technology, BHP Billiton, Houston, Texas 77056, USA \\ ${ }^{9}$ Department of Earth and Planetary Sciences, Harvard University, 20 Oxford Street, Cambridge, Massachusetts 02138, USA \\ ${ }^{10}$ Department of Physics and Princeton Center for Theoretical Science, Princeton University, Princeton, New Jersey 08544, USA \\ *Corresponding author. E-mail: macphers@si.edu
}

(Received 15 October 2012; revision accepted 23 May 2013)

\begin{abstract}
A new meteorite find, named Khatyrka, was recovered from eastern Siberia as a result of a search for naturally occurring quasicrystals. The meteorite occurs as clastic grains within postglacial clay-rich layers along the banks of a small stream in the Koryak Mountains, Chukotka Autonomous Okrug of far eastern Russia. Some of the grains are clearly chondritic and contain Type IA porphyritic olivine chondrules enclosed in matrices that have the characteristic platy olivine texture, matrix olivine composition, and mineralogy (olivine, pentlandite, nickel-rich iron-nickel metal, nepheline, and calcic pyroxene [diopsidehedenbergite solid solution]) of oxidized-subgroup CV3 chondrites. A few grains are finegrained spinel-rich calcium-aluminum-rich inclusions with mineral oxygen isotopic compositions again typical of such objects in CV3 chondrites. The chondritic and CAI grains contain small fragments of metallic copper-aluminum-iron alloys that include the quasicrystalline phase icosahedrite. One grain is an achondritic intergrowth of $\mathrm{Cu}-\mathrm{Al}$ metal alloys and forsteritic olivine \pm diopsidic pyroxene, both of which have meteoritic (CV3-like) oxygen isotopic compositions. Finally, some grains consist almost entirely of metallic alloys of aluminum + copper \pm iron. The $\mathrm{Cu}-\mathrm{Al}-\mathrm{Fe}$ metal alloys and the alloy-bearing achondrite clast are interpreted to be an accretionary component of what otherwise is a fairly normal CV3 (oxidized) chondrite. This association of CV3 chondritic grains with metallic copperaluminum alloys makes Khatyrka a unique meteorite, perhaps best described as a complex CV3 (ox) breccia.
\end{abstract}

\section{INTRODUCTION}

A meteorite was found as a result of an expedition to Chukotka in far eastern Russia by ten scientists from the
United States, Russia, and Italy, from July 20 to August 7, 2011. The goal was to search for naturally occurring quasicrystals - solids with quasiperiodic arrangements of atoms exhibiting Bragg peak diffraction and symmetries 
forbidden for periodic crystals (Levine and Steinhardt 1984; Shechtman et al. 1984). The first natural quasicrystal to have been identified, icosahedrite $\left(\mathrm{Al}_{63} \mathrm{Cu}_{24} \mathrm{Fe}_{13}\right)$, was recently discovered by Bindi et al. $(2009,2011)$ in a rock sample in the collections of the Museo di Storia Naturale of the Università degli Studi di Firenze (hereafter, MSNF), after a decade-long search (Lu et al. 2001). The Florence museum sample is one of two tiny $(<0.5 \mathrm{~cm})$ rocks known to contain the crystalline copper-aluminum alloys khatyrkite $\left(\mathrm{CuAl}_{2}\right)$ and cupalite $(\mathrm{CuAl})$. The second sample known to contain these alloys is deposited as the holotype sample for both alloys (Razin et al. 1985), at the St. Petersburg Mining Institute. Both samples were found in 1979 by V. V. Kryachko, in clay-rich layers along the banks of the Listvenitovyi stream in the Khatyrka ultramafic zone within the Koryak Mountains, Chukotka Autonomous Okrug of far eastern Russia. The MSNF sample (described in detail below) exhibits a remarkably complex set of assemblages, with a metallic core containing icosahedrite, khatyrkite, cupalite, and $\beta$-phase $(\mathrm{AlCuFe})$, all intergrown with diopside, forsterite, and minute amounts of stishovite. This core is encased in a very fine-grained white rind that consists of spinel, calcic pyroxene ranging in composition from diopside to hedenbergite, nepheline, and sodalite. Preliminary oxygen isotopic analysis via SIMS at Caltech showed the silicates and oxides to have isotopic compositions overlapping those of anhydrous phases in carbonaceous chondrite meteorites (Bindi et al. 2012). However, even with the isotopic data in hand, the mechanism that produced this exotic assemblage (meteorite $+\mathrm{Cu}$-Al-Fe-bearing metal) remained uncertain. Because the limited material available in this single sample was insufficient to settle these issues and because the holotype specimen is not available for examination, more samples and a geologic study of the discovery locality were needed. It was for this reason that the 2011 expedition to Chukotka was undertaken. It led to discovery of more meteorite material and associated $\mathrm{CuAl}$ metals.

From the material processed during the expedition, a total of nine grains (so far) have been identified to contain copper-aluminum alloys. Of these, seven contain sufficient silicate materials to be identifiable via scanning electron microscope (SEM) and isotopic analysis as meteoritic. The remaining two consist of copper-aluminum metal only and their probable meteoritic nature is inferred by association. Four of the largest meteorite grains have the properties of $\mathrm{CV} 3$ chondrites, detailed below, but the presence of $\mathrm{Cu}-\mathrm{Al}$ alloys may mean that they are complex breccias containing a previously unknown type of meteoritic material. Based on their resemblance to one another and their co-occurrence in a thin $(<10 \mathrm{~m})$ unconsolidated sedimentary sequence, we conclude that all are from a single fall that we have named Khatyrka.

The name derives from the Khatyrka River, which is one of the main drainage rivers in the Koryak Mountains. That river is also the namesake of the mineral, khatyrkite, which gives an added symmetry to the meteorite name. Khatyrka has been approved by the Nomenclature Committee of the Meteoritical Society, and a report is available online in the Meteoritical Bulletin Database. Representative specimens are on deposit at the U.S. National Museum of Natural History, Smithsonian Institution, Washington D.C.

\section{GEOLOGIC SETTING}

The location of the field area, in the Koryak Mountains, is shown in Figure 1. The site is located 290 $\mathrm{km} \mathrm{SW}$ of the city of Anadyr along the banks of the Listvenitovyi stream $\left(62^{\circ} 39^{\prime} 11.36^{\prime \prime} \mathrm{N}, 174^{\circ} 30^{\prime} 1.54^{\prime \prime} \mathrm{E}\right.$; see Fig. 1b). The Listvenitovyi feeds into the Iomrautvaam River that, in turn, feeds into the Khatyrka. The meteorite fragments occur as clastic grains within a sequence of unconsolidated clay-rich layers (described below) that are exposed at different points along the sides of the Listvenitovyi. A geologic map of the drainage region around the Listvenitovyi stream is given in Fig. 2.

The Koryak Mountains are a northeast-striking mountain range along the Eurasian coast of the Bering Sea. They define a fold and thrust belt that is interpreted to have formed through the accretion of a series of exotic terranes along an active convergent plate margin during the Late Mesozoic and Early Cenozoic (Stavsky et al. 1990).

Within the study area, three distinct lithologic units make up the bedrock. Going from northwest to southeast (across strike) of the range, these are: (1) a greenschist facies sequence of phyllites and schists of inferred Precambrian (?) age; (2) a belt of serpentinite with included blocks of chert and minor limestone, interpreted as a mélange of probable Cenozoic age; and (3) a coarsening upward sequence of shale and sandstone, which contains the Cretaceous-Cenozoic boundary sequence according to Russian geologic maps (e.g., State Geological map of Russian Federation 1976). All three units dip predominately to the northwest.

None of the contacts between adjacent rock units are exposed due to the poor outcrop conditions that are typical of far northern alpine regions. However, the contacts between each of the three units are inferred to be thrust faults. This interpretation is supported by the fact that unmetamorphosed sedimentary rocks are 

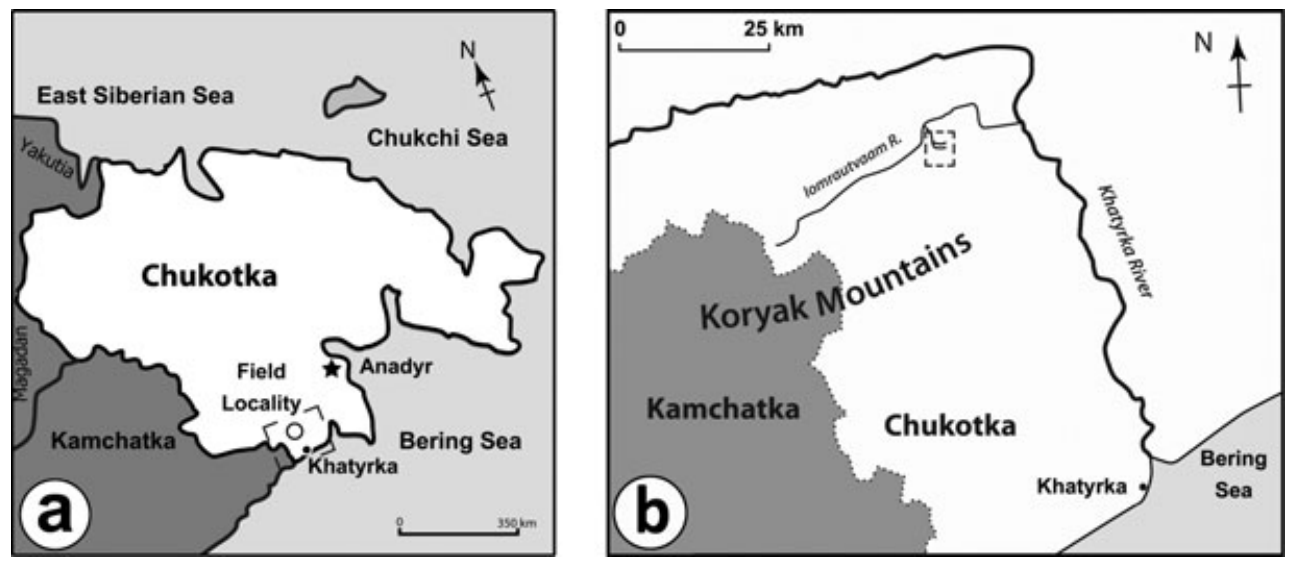

Fig. 1. a). Map of the find locality in Chukotka in the northern half of the Kamchatka peninsula in far eastern Russia. The distance between Anadyr and the field locality is about $280 \mathrm{~km}$; b) Enlarged map of the find locality in the Koryak Mountains. The dashed rectangular outline shows the location of the geologic map in Fig. 2.

\section{Geological Map of Listvenitovyi Stream Area, Koryak Mountains, Chukotka, Russia}

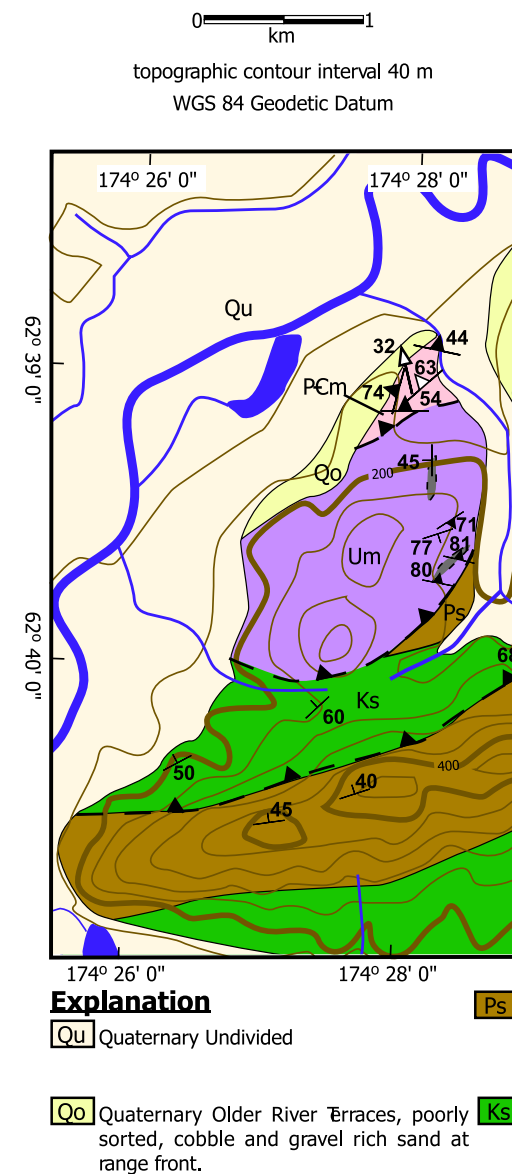

topographic contour interval $40 \mathrm{~m}$ WGS 84 Geodetic Datum
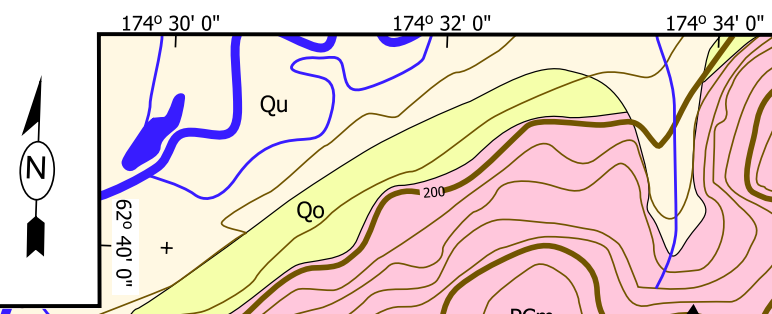

$174^{\circ} 36^{\prime} 0^{\prime \prime}$
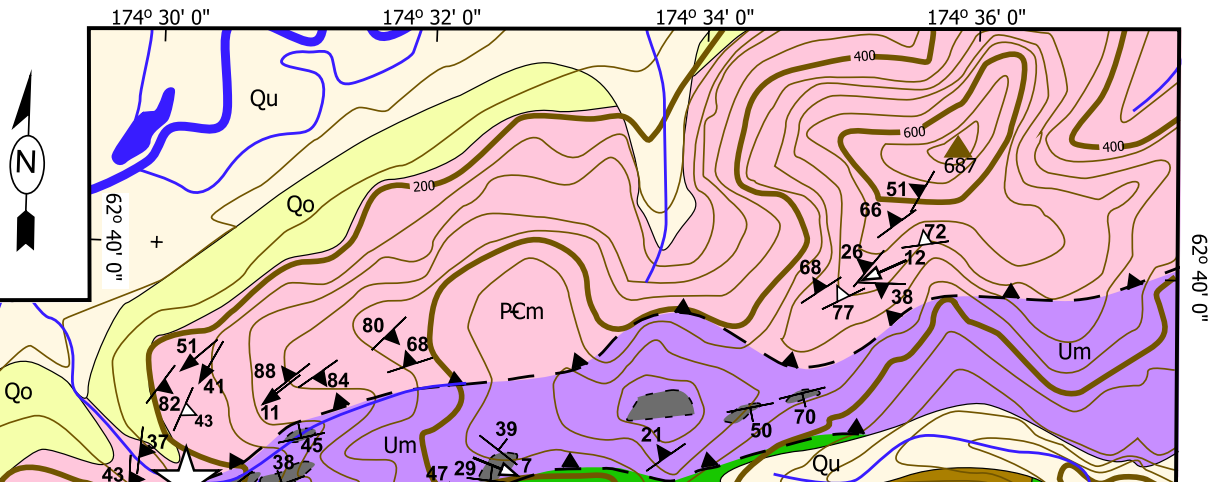
structurally beneath the ultramafic mélange, and the mélange lies below metamorphic rocks of probable continental affinity.

Our mapping focused on the ultramafic mélange unit and its contacts with adjacent rock units, because these rocks have similar mineralogy to the silicates in the MSNF sample and therefore a genetic connection between the MSNF sample and the ultramafic rocks was considered a possibility. However, the ultramafic rocks contain abundant secondary minerals (serpentine group minerals, talc, and minor amphibole) that are lacking in the MSNF specimen. More importantly, the oxygen isotopic analyses described below demonstrate an extraterrestrial origin for the silicates associated with the quasicrystals and therefore a genetic connection between the MSNF specimen and the ultramafic rocks is no longer considered possible.

The surficial geology of the study area is dominated by glacial and alluvial sediments that are found along the banks and flood plains of the streams and rivers. The fine-grained sedimentary beds that contain the meteoritic material are within the glacial and alluvial deposits that are exposed along the banks of the Listvenitovyi stream where it has cut down to bedrock. Chemical analysis by X-ray fluorescence shows that the clay-rich materials are of diverse compositions and were derived from two different sources. One type of clayrich sediment has a chemical composition most similar to shale or upper crustal metamorphosed igneous rocks, being relatively enriched in silica, alkalis, and aluminum. The second type of clay-rich sediment is much poorer in silica, and enriched in $\mathrm{Mg}, \mathrm{Ni}$, and $\mathrm{Cr}$, suggesting that it is derived from weathering of the serpentinite. The presence of meteoritic material in the two chemically distinct sediment types is consistent with reworking and redistribution of the meteorite fragments by the Listvenitovyi stream. The sediments hosting the grains are deposited in a v-shaped valley that is cut into glacial topography. Given this relationship, we inferred that the sediments are younger than the last glacial maximum in the Koryak Mountains (10 ka; Gualtieri et al. 2000). This inference was later confirmed by radiocarbon age dating of a sample of a serpentinitebearing clay-rich sediment (see below).

\section{RECOVERY}

The trip to the Listvenitovyi stream took 4 days by snow-cat (tracked vehicle) from Anadyr, over the tundra and mountains. After reaching the site and surveying the conditions, a deployment plan of three scientific teams was set: (1) the search team, which identified promising sites along the streambed, excavated 1.5 tons of the source sediment, and, then, disaggregated and panned the sediment to obtain the heavy fraction that might include the hoped-for additional samples of khatyrkite, cupalite, and icosahedrite; (2) an analysis team to examine the heavy fraction and identify the most promising and scientifically interesting grains; and (3) the field team, which surveyed the geology of the local mountains and the sources of the sediment that feed the Listvenitovyi. Figure 3 shows details of the stream and panning operations. The team returned by snow-cat, leaving the Koryaks just one day before the first snows of the season blanketed the region in mid-August.

The clay-rich layers are exposed in multiple locations along the sides of the Listvenitovyi stream, and range from blue to green to tan in color. Figure 3a shows an excavated exposure of the blue variant, here occurring as an approximately $8-10 \mathrm{~cm}$ thick layer. When freshly excavated and wet (e.g., Fig. 3b), the clay is very dense and sticky and in general has the gross attributes of potter's clay. For this reason, the panning (Fig. 3c), which was carried out by conventional placer techniques, required that the clay first be placed in hot water for manual disaggregation. Each panning cycle processed approximately $20 \mathrm{~kg}$ of bulk material, much of which was fine clay, and resulted in a small amount of dark millimeter-sized or smaller grains in an evaporation dish (Fig. 3d). The heavy fraction from each panning cycle was individually bagged (i.e., one bag per dish). The contents of each bag were examined visually at the camp site with a microscope, looking primarily for metallic grains or grains that obviously contained metal. Promising candidates were set aside and bagged separately. All of the bags were taken to Italy and, later, Princeton, for further grain selection. Nine of the most promising grains were identified for further analysis. As noted above, two of these were entirely metal, four contained sufficient attached silicate material to clearly establish a meteoritic origin, and another three probably are meteoritic as well.

All of the recovered meteorite and metal grains are a few $\mathrm{mm}$ or less in maximum dimension and $<0.01 \mathrm{~g}$ in mass. The total meteoritic mass recovered is $<0.1 \mathrm{~g}$. The descriptions and analyses that follow primarily are based on the largest grains, which contain the greatest fraction of meteoritic material.

One several-hundred-gram sample of the blue serpentinite-rich clay was collected and preserved intact for sedimentologic studies and, especially, radiocarbon dating.

\section{ANALYTICAL METHODS}

As noted previously, their small sizes and rarity mandated that the meteorite grains studied herein were 

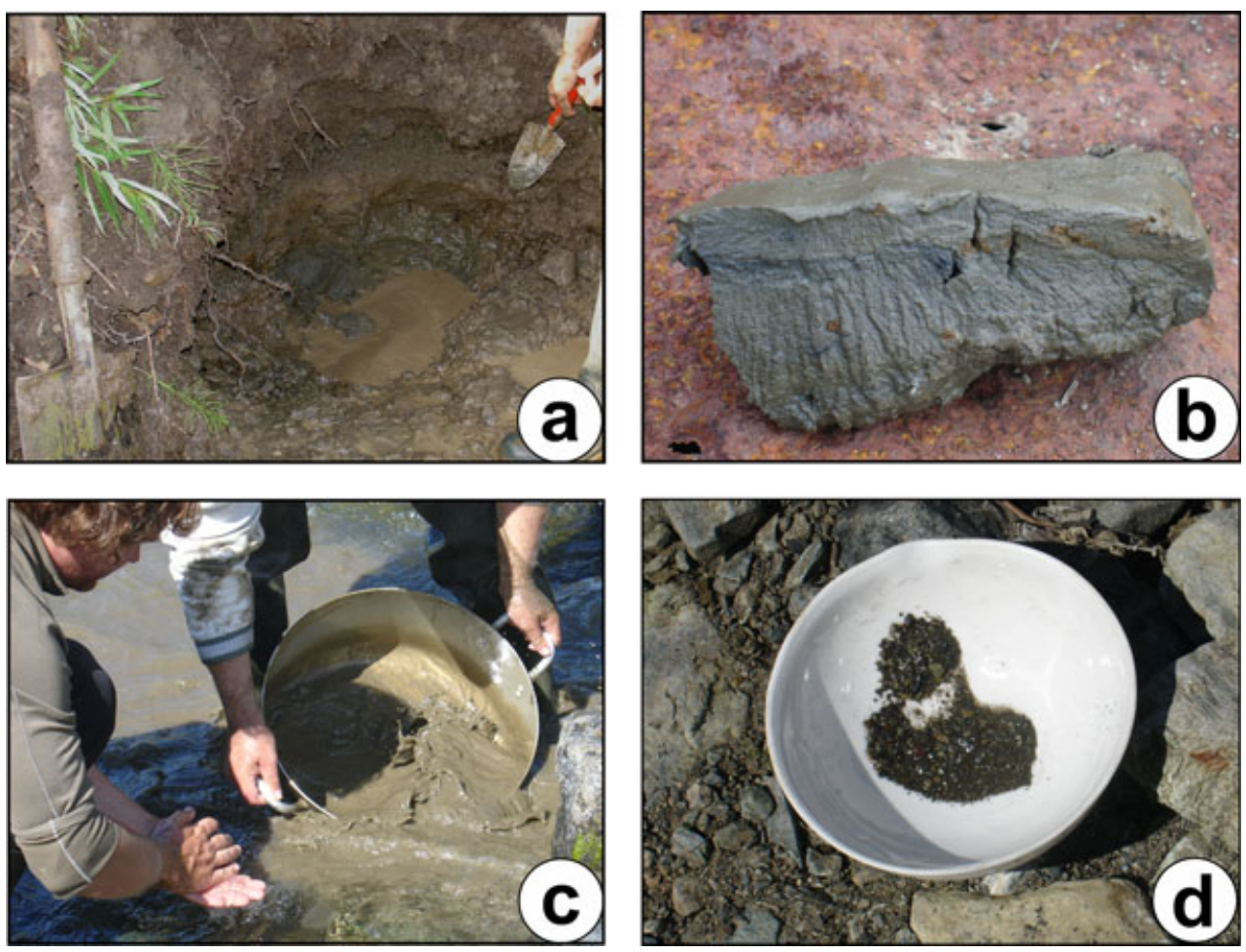

Fig. 3. Field photos: a) the blue variety of clay in place, visible just above the water level; b) a piece of freshly extracted blue clay (length of sample approximately $13 \mathrm{~cm}$ ); c) the panning operation; and d) residue after panning approximately $20 \mathrm{~kg}$, in an evaporation dish (diameter approximately $10 \mathrm{~cm}$ ).

embedded in epoxy resin and prepared as polished thick sections; hence, no optical properties of the minerals were determined. Grain \#121 (described below) was polished twice, first very lightly just to expose the grain surface for initial SEM examination. A second polish subsequently was carried out to expose more of the grain for additional detailed study. The fine-grained white "rind" on the original Florence (MSNF) sample was prepared into polished grain mounts for study by SEM, electron microprobe, and SIMS.

High-resolution backscattered electron (BSE) images of polished sections were obtained using the FEI NOVA NanoSEM 600 SEM at the Smithsonian Institution, operated at $15 \mathrm{keV}$ with a sample current of 2-3 nA. The SEM is equipped with a Thermo-Noran energy dispersive (EDS) X-ray analytical system, and data are stored and processed using Thermo-Scientific Noran System Six software. The System Six software allows for full-spectrum imaging, in which a complete energy-dispersive spectrum is collected and stored for each pixel within a map. The EDS analyses of matrix olivines were collected using this system, to take advantage of the high spatial resolution imaging and digital beam location for analysis of such small grains.

Most mineral compositions were measured with a JEOL JXA-8900 automated five-spectrometer wavelength-dispersive (WDS) electron microprobe at the Smithsonian Institution, operated at $15 \mathrm{keV}$ accelerating potential, 15-20 nA beam current, and counting times in the range of 10-40 s (depending on the element). Natural and synthetic minerals were used both for calibration and as running standards to monitor data accuracy.

The magnesium and some of the oxygen isotopic data were first reported by Bindi et al. (2012), and are reproduced here for completeness. Details of the methods used are given in Bindi et al. (2012). In brief, the oxygen isotopic measurements were made using both the Cameca NanoSIMS 50L and the Cameca ims7f geo ion microprobes, both at Caltech. Those made with the ims-7f geo employed a $0.2 \mathrm{nA}$ primary ion beam with an approximately $15 \mu \mathrm{m}$ spot size, giving a typical precision $(2 \sigma)$ of approximately $2-2.5 \%$ for both ${ }^{17} \mathrm{O}$ and ${ }^{18} \mathrm{O}$. The ims-7f was operated in peak-jumping mode, using a Faraday cup for ${ }^{16} \mathrm{O}^{-}$and an electron multiplier for ${ }^{17} \mathrm{O}^{-}$and ${ }^{18} \mathrm{O}^{-}$, at a mass resolving power (6500) sufficient to resolve ${ }^{16} \mathrm{OH}^{-}$interference on ${ }^{17} \mathrm{O}^{-}$. The NanoSIMS $50 \mathrm{~L}$ was operated in multicollection mode, using a smaller $(3 \times 3 \mu \mathrm{m})$ and weaker (approximately $30 \mathrm{pA}$ ) primary ion beam that resulted in less precise measurements (approximately $4 \%$ for ${ }^{17} \mathrm{O}$ and approximately $8 \%$ for ${ }^{18} \mathrm{O}, 2 \sigma$ ). For further details regarding standards etc., see Bindi et al. (2012). 

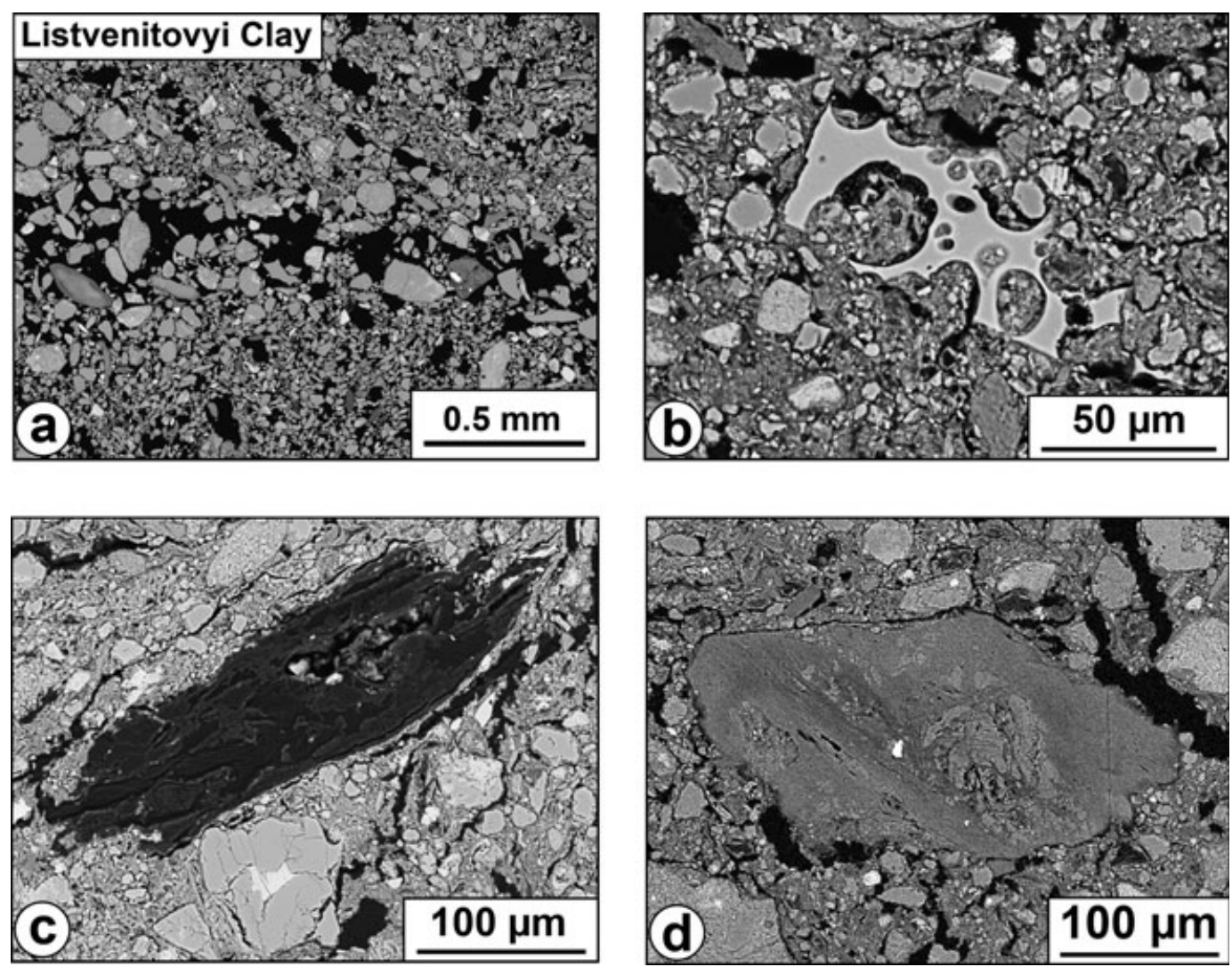

Fig. 4. Backscattered electron images of the fine fraction of the blue clay, showing layering (a), a silicic volcanic glass shard (b), a charcoal fragment (c), and a serpentinite clast (d).

An attempt was made to search for extinct ${ }^{26} \mathrm{Al}$ in Grain \#123, one of the largest natural metal grains that measures approximately $221-286 \mu \mathrm{m}$ in maximum size (described below). We used the ims-7f geo, employing a $0.1 \mathrm{nA} \mathrm{O}^{-}$primary beam focused into a $<5-\mu \mathrm{m}$ diameter spot, and operating at a mass resolving power of approximately 4000. Matrix effects and sensitivity factors were evaluated using synthetic $\mathrm{Cu}-\mathrm{Al}$ alloys. Instrumental and intrinsic mass fractionation in both ${ }^{25} \mathrm{Mg}$ and ${ }^{26} \mathrm{Mg}$ were calculated using a linear law, and the data are reported in standard delta notation:

$$
\delta^{26} \mathrm{Mg}=\Delta^{26} \mathrm{Mg}-2 \Delta^{25} \mathrm{Mg}
$$

where

$$
\Delta^{25,26} \mathrm{Mg}=\left[\frac{{ }^{25,26} \mathrm{Mg}(\text { unknown })}{{ }^{25,26} \mathrm{Mg}(\text { standard })}-1\right] \times 1000
$$

For further details see Bindi et al. (2012).

${ }^{14} \mathrm{C}$ ages of a sample of the blue clay variety and its enclosed charcoal fragments were determined at the Accelerator Mass Spectrometry Laboratory, University of Arizona. Details of the technique and the general principles involved are summarized in Donahue et al.
(1990) and McGeehin et al. (2001). For the charcoal, the sediment sample was sieved to $>63 \mu \mathrm{m}$ and rootlets were picked from the sample. The charcoal in the sediment was fine-grained and disseminated. The sample was pretreated in acid to dissolve any carbonates, then rinsed thoroughly and dried. The dried sample was combusted at $400{ }^{\circ} \mathrm{C}$ under a partial vacuum containing oxygen to convert the carbon to $\mathrm{CO}_{2}$. The $\mathrm{CO}_{2}$ was reduced to graphite and run on the AMS as described in Burr and Jull (2010). Measurements were also made on the $<64 \mu \mathrm{m}$ fraction. These were prepared as described by McGeehin et al. (2001), with a lowtemperature $\left(\mathrm{LT}, \quad<400{ }^{\circ} \mathrm{C}\right)$ and a high-temperature (HT, $>400{ }^{\circ} \mathrm{C}$ ) fraction. Ages are reported as ${ }^{14} \mathrm{C}$ years before present (BP), where present is defined by convention as 1950. Also, by convention, radiocarbon ages are reported with $1 \sigma$ errors (Stuiver and Polach 1977).

\section{RESULTS}

\section{Sample Descriptions}

Backscattered electron images of the blue variant of the host clay are given in Fig. 4. It is very fine-grained 

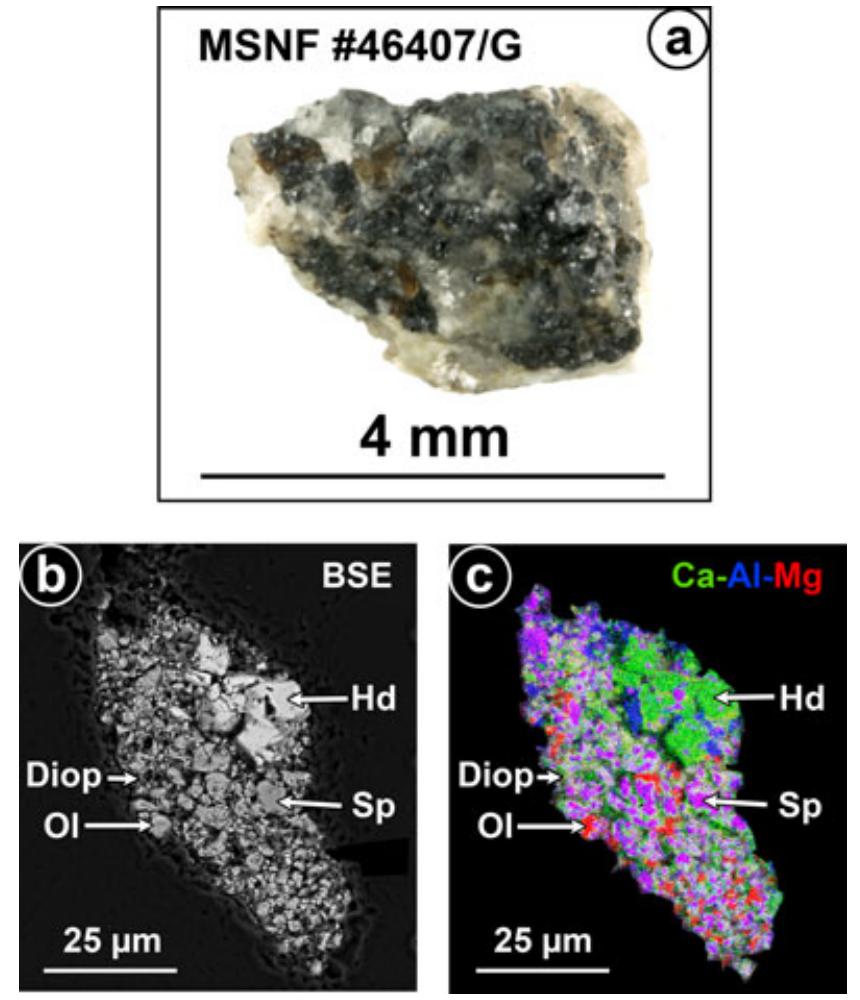

Fig. 5. a) Incident light image of entire MSNF specimen prior to sampling; b) BSE image of one representative grain from the white outer rind of MSNF sample. Bright rectangular crystals are hedenbergite (Hd). Olivine (Ol), spinel (Sp), and diopside (Di) are indistinguishable in BSE; c) Ca-Al-Mgcombined X-ray area map of grain shown in (b). In this image, spinel is magenta, olivine is red, diopside and hedenbergite are both green, and the deep blue areas (unlabeled) are nepheline and sodalite.

and has subtle layering (Fig. 4a). The grains primarily are lithic clasts, a variety of which are present, including minor amounts of very fresh rhyolitic ash (Fig. 4b) and

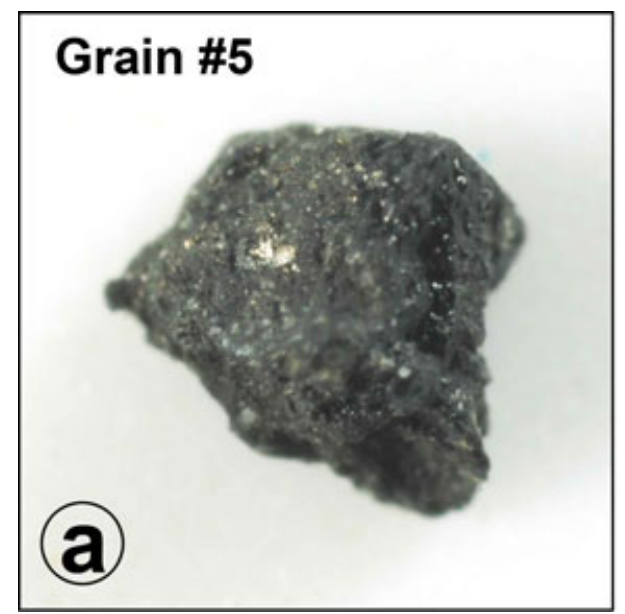

charcoal fragments (Fig. 4c). However, the dominant lithology in the blue variant is serpentinite (Fig. 4d), which probably accounts for its blue color when fresh. The green and tan varieties of the clay are quite different in composition; they contain mainly shale clasts and mineral grains, rather than serpentinite. A critical point is that meteorite and $\mathrm{Cu}-\mathrm{Al}$ metal grains were found in all variants of the clay.

The original MSNF sample $(\# 46407 / \mathrm{G})$ is shown in Fig. 5. The metal is concentrated in the core of the grain (Fig. 5a), and the whole is enclosed in a white rind. BSE and X-ray area maps (Figs. 5b, c) reveal this white rind to consist of very fine-grained diopside, olivine, spinel $\left(\mathrm{MgAl}_{2} \mathrm{O}_{4}\right)$, hedenbergite, sodalite, and nepheline. The diopside forms very thin rims around spinel, whereas the hedenbergite occurs as larger blocky grains. These textures are similar in most respects to those observed in fine-grained spinel-rich calciumaluminum-rich inclusions in CV3 carbonaceous chondrites. The principal differences are an overall finer grain size and much thinner diopside rims around spinel in the Khatyrka grain. The interior of the MSNF sample is a dense, achondritic intergrowth of metal with forsteritic olivine and diopside. The texture is illustrated in Bindi et al. (2012).

The meteorite grains that were recovered from the 2011 expedition are dark gray in incident light with diverse silicate and metallic fragments visible (Fig. 6). No fusion crust is preserved on the samples examined thus far. SEM examination of the grain surfaces revealed the presence of $\mathrm{Cu}-\mathrm{Al}$ alloy grains (Fig. 7). Detailed SEM examination of polished surfaces of two of the grains (labeled herein \#5 and \#121) reveals clearly the chondritic character (Fig. 8) of both fragments, very probably from the same meteorite. Both consist (Fig. 8) of olivine-rich chondrules, chondrule fragments, and isolated olivine crystals in a porous

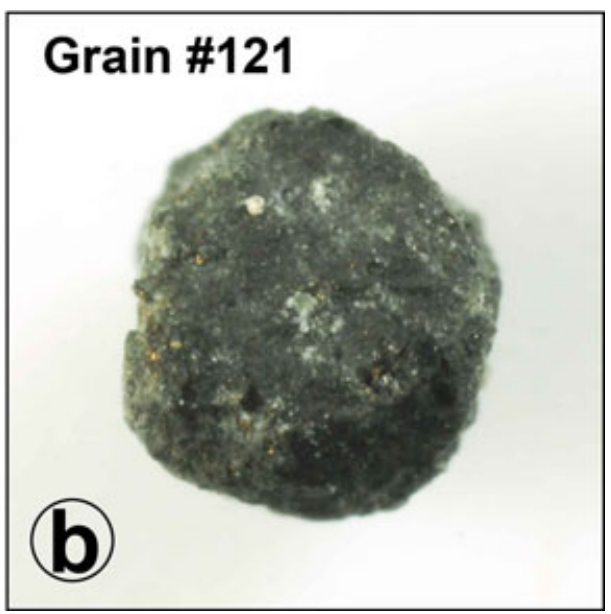

Fig. 6. Incident-light photographs of grains \#5 and \#121. The width of field in both cases is slightly more than $1 \mathrm{~mm}$. 


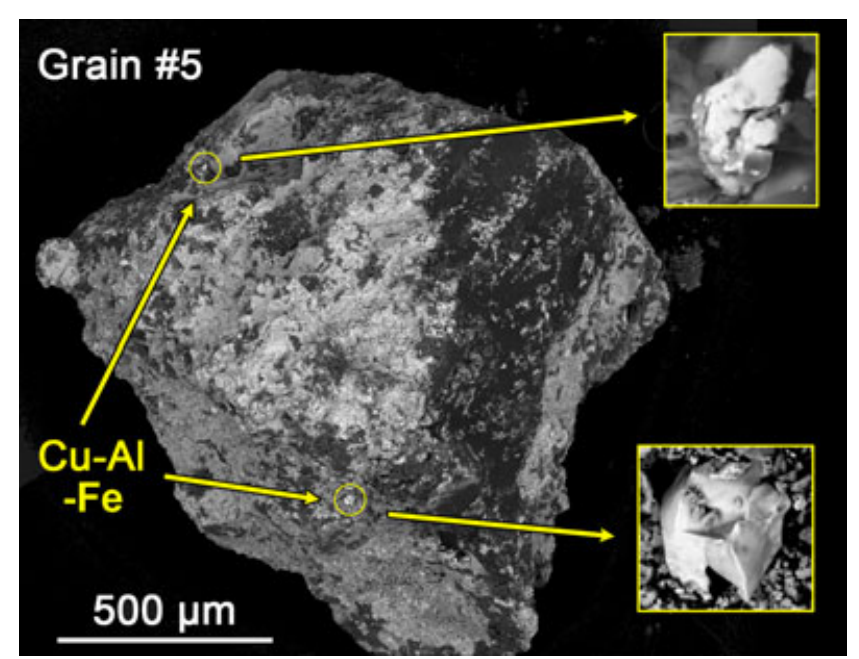

Fig. 7. Backscattered electron image of the whole grain \#5 showing two copper-aluminum-iron (Cu-Al-Fe) metal grains attached to the surface.

matrix of olivine, calcium-rich clinopyroxene of diverse composition, nepheline, Ni-Fe metal, and Ni-Fe sulfide.

All of the chondrules in our samples are of the type IA porphyritic olivine variety, although, given the small size of the meteorite fragments and the limited number of chondrules, this sampling probably is not representative of the original meteorite. The largest chondrule we observed is just under one $\mathrm{mm}$ in maximum size (Fig. 9). Irregularly shaped olivine phenocrysts are enclosed by enstatite-rich pyroxene. The olivines have forsterite cores that show slight zoning outward (see below), but outermost on all the crystals are very iron-rich olivine mantles (Fig. 10a) whose contacts with the underlying forsterite are sharp. Note that this ferroan overgrowth extends along internal crystalline fractures (Fig. 10a), demonstrating that it is a secondary feature. Identical ferroan olivine rims and vein structures have been described in many previous studies of oxidized-subgroup CV3 chondrites [CV3 (ox)], for example, Peck and Wood (1987), Weinbruch et al. (1990), and Krot et al. (1998). Interstitial to the olivine is primary enstatite (Figs. 9 and 10a) that also is rimmed by iron-rich olivine. The matrix texture (Fig. 10b) is distinctive to the point of being definitive regarding the CV3 (ox) nature of the chondritic material. The matrix is highly porous and is nearly identical to that observed in $\mathrm{CV} 3$ chondrites, such as Allende. The olivine crystals that make up most of the matrix appear to be rod- and even barrel-shaped in Fig. 10b, but, in fact, they are plates in three dimensions. The composition of the matrix olivine (see below) is identical to that of the iron-rich rims around the chondrule olivine phenocrysts and also to that of matrix olivine in CV3 (ox) chondrites, such as Allende. The
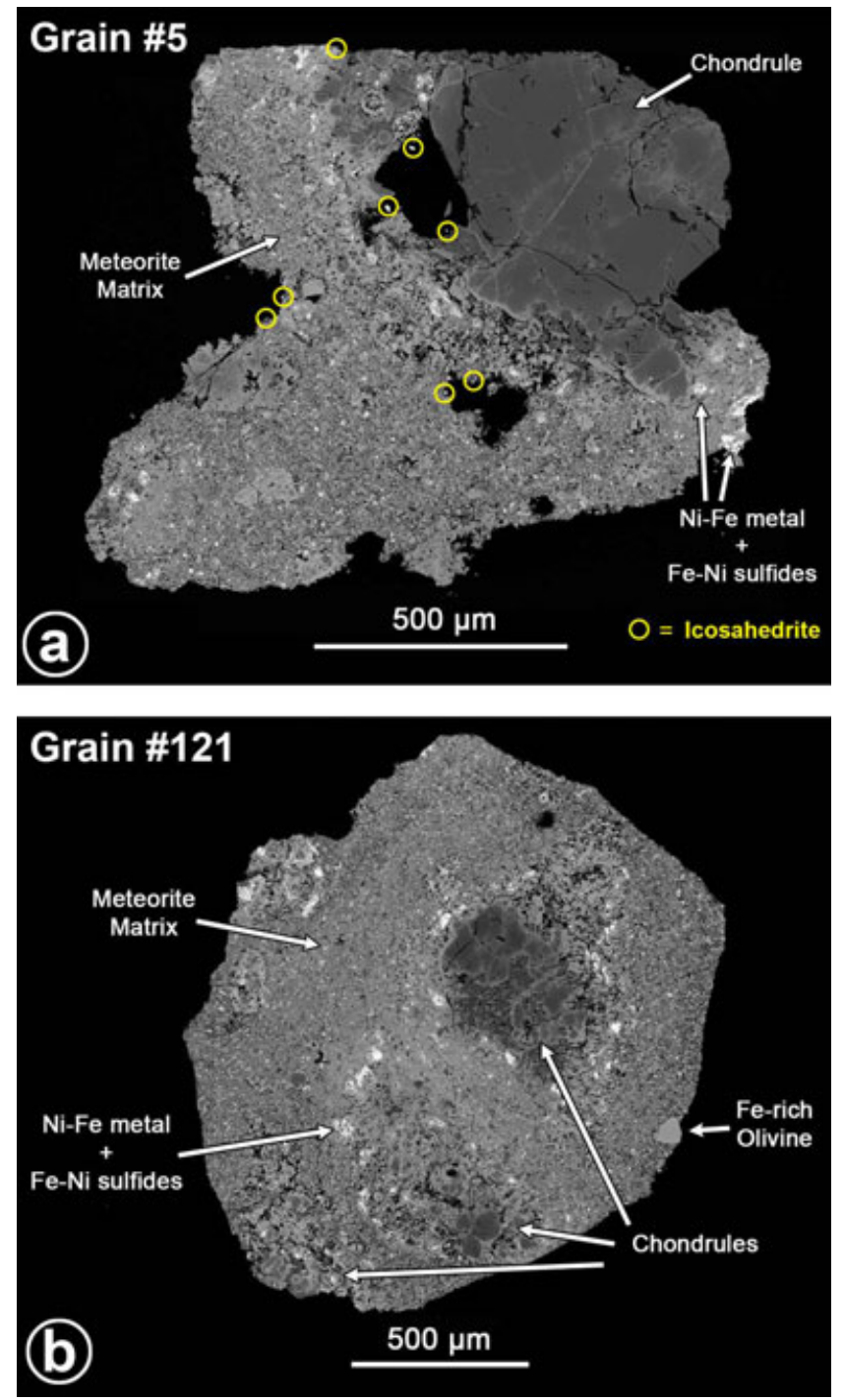

Fig. 8. Backscattered electron images of polished sections of grains \#5 a) and \#121 b), showing porphyritic olivine chondrules embedded in characteristic CV3 meteorite matrix. Grain \#5 has a number of $\mathrm{Cu}-\mathrm{Al}-\mathrm{Fe}$ grains attached to its surface (the "holes" are likely re-entrants from the third dimension). The alloy grains are mainly icosahedrite, identified as such based on having compositions identical to a structurally determined icosahedrite crystal from this same grain.

additional presence of Ni-rich iron metal, both Ni-poor (troilite) and Ni-rich (pentlandite) iron sulfides, interstitial nepheline, and abundant clumps of Ca-rich clinopyroxene (highly variable $\mathrm{Fe} / \mathrm{Mg}$ ) is again typical of CV3 carbonaceous chondrites. Magnetite has not been found, although with such small meteorite fragments, we cannot rule out the possibility of nonrepresentative sampling. Most of the $\mathrm{Cu}-\mathrm{Al}$ alloy particles appear to be attached to the outside surfaces of the grains (Fig. 8a), but one cupalite particle is enclosed within the olivine of a chondrule (Fig. 9) and is shown in detail in Fig. 10c. 


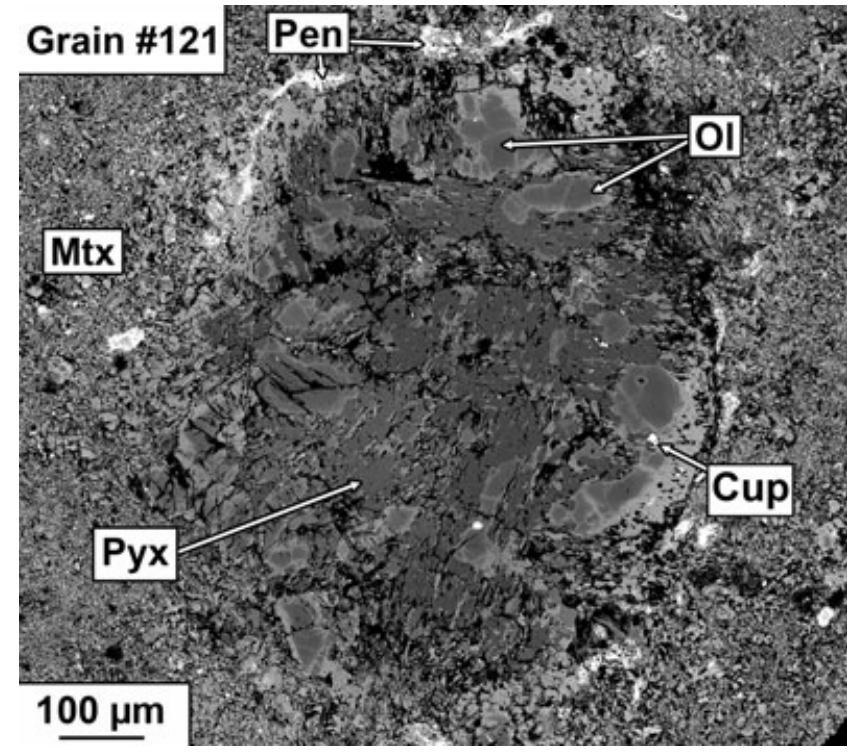

Fig. 9. Backscattered electron image of a porphyritic olivine chondrule in grain \#121, showing irregular olivine crystals enclosed within enstatite. Bright rims around and veins within olivine are iron-rich and have very sharp boundaries with the underlying magnesian olivine. A small grain of cupalite (Cup) metal is enclosed with the olivine crystal at right. This image was taken prior to the second polishing of this grain; the image in Fig. $8 \mathrm{~b}$ was taken afterward. Mtx, meteorite matrix; Ol, olivine; Pyx, enstatite pyroxene; Pen, pentlandite.

Metal and pentlandite occur together with calcium phosphate (probably whitlockite) in distinctive rounded (in some cases concentric) masses (Fig. 11). The sulfide and phosphate assemblage encloses irregular particles of metal, suggesting secondary replacement of the metal. These assemblages are similar in many respects to the run products from experimental sulfidization of homogeneous metal (Schrader and Lauretta 2010), suggesting the Khartyrka metal-sulfide-phosphate masses also originated as simple metal grains.

Among the meteorite grains recovered is another fragment (grain \#122) of a calcium-aluminum-rich inclusion (CAI; Figs. 12 and 13). It is nearly identical to

Fig. 10. Detailed BSE images of grain \#121: a) forsteritic olivine in chondrules is mantled by an overgrowth of ferroan olivine; b) the porous matrix consists mostly of tiny plates (appearing as rods in cross section) of olivine, along with sulfide, clumps of calcium-rich pyroxene, and sporadic interstitial nepheline; c) the original lightly polished surface of grain \#121 shows a tiny grain of cupalite (Cup) with attached pentlandite and nickel-rich metal (Ni-Met), all enclosed within an olivine crystal inside a chondrule; this specific grain is indicated in Fig. 9. The dark region surrounding the grain is a depression in the surrounding olivine, owing to this not being a fully polished surface.
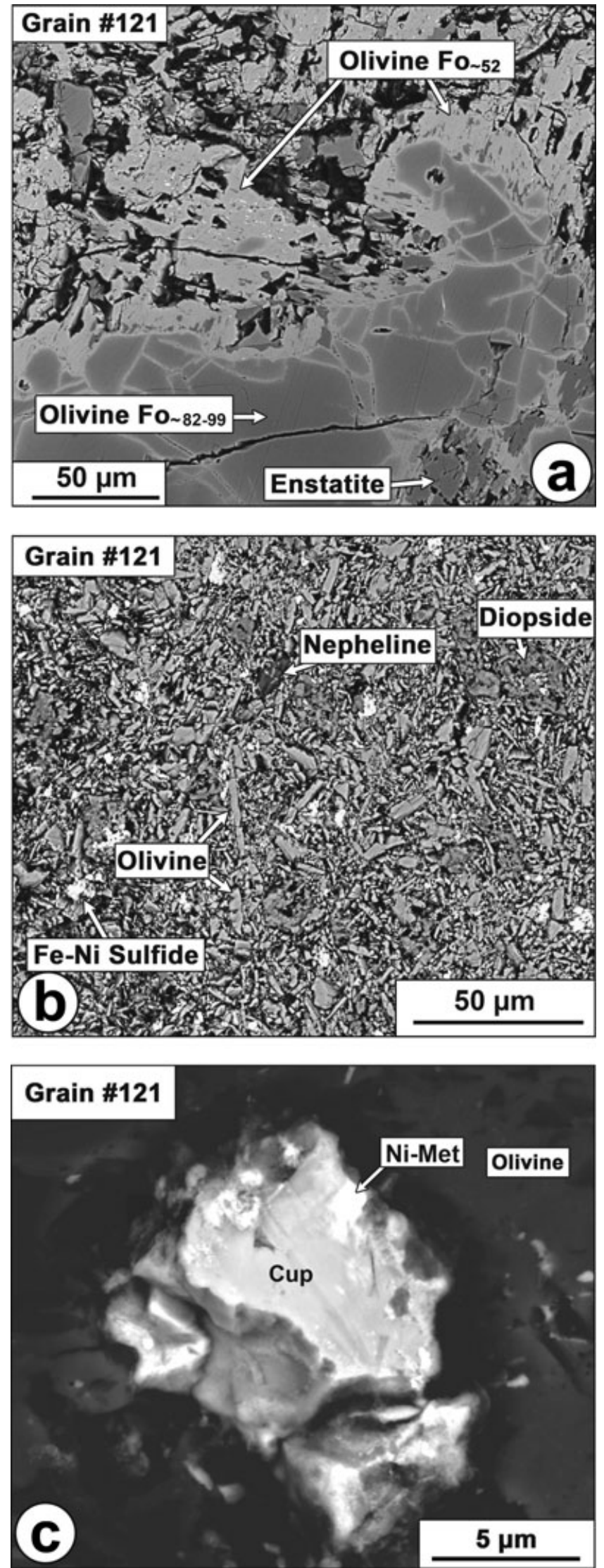

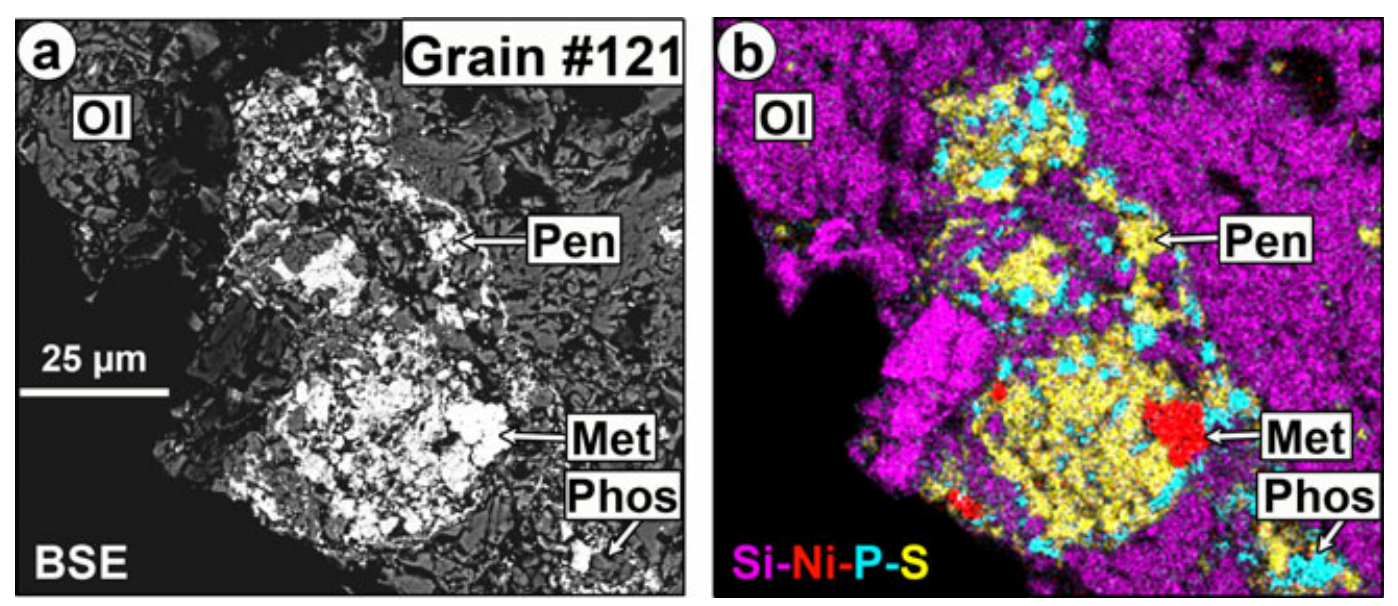

Fig. 11. Paired BSE and combined S-Ni-P-S X-ray area map of a nodular intergrowth of Fe-Ni metal (Met), pentlandite (Pen), and Ca-phosphate (Phos) enclosed within a chondrule that is mostly olivine (Ol). The phosphate is indistinguishable from the silicate on the BSE image, but shows up clearly as sky-blue grains in the X-ray map. Such nodules are characteristic of Khatyrka.

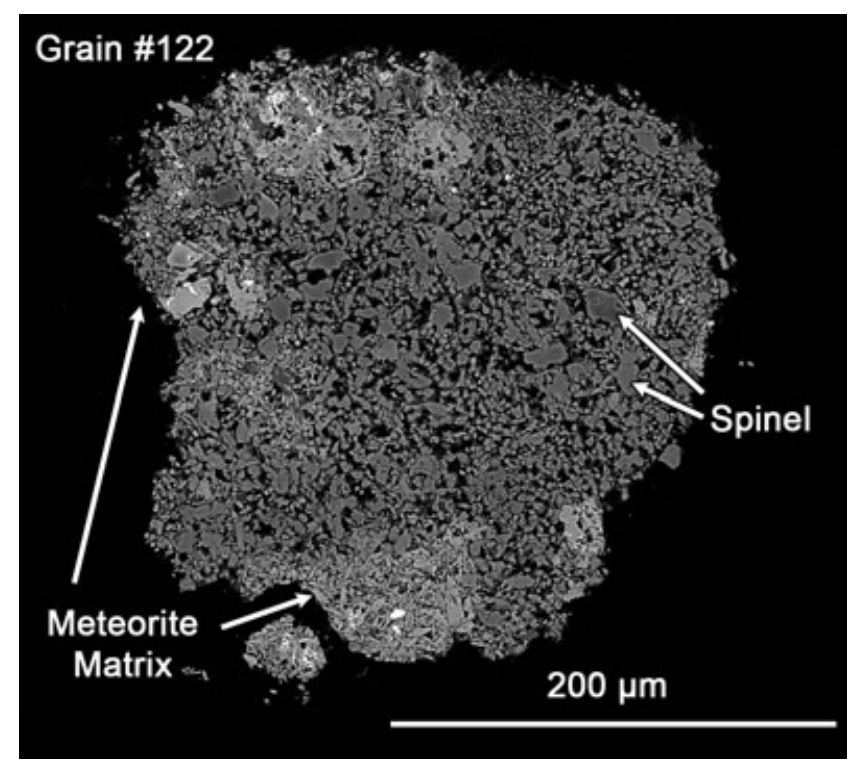

Fig. 12. Backscattered electron image of grain \#122, a porous aggregate of spinel grains with surrounding patches of CV3 meteorite matrix. Sporadic white grains are pentlandite and $\mathrm{Ni}-\mathrm{Fe}$ metal.

the white material in MSNF $\# 46407 / \mathrm{G}$ in texture and mineralogy, except that this grain also has attached portions of meteorite matrix (Fig. 12) identical to that in grains $\# 5$ and $\# 121$. Although not exposed in thin section, grain \#122 also had grains of $\mathrm{Cu}-\mathrm{Al}$ metal exposed on its surface. The interior (Fig. 13a) is a porous aggregate of spinel grains, each rimmed by thin layers of aluminous diopside that are most clearly seen in the $\mathrm{Ca}-\mathrm{Al}-\mathrm{Mg}$ combined $\mathrm{X}$-ray in Fig. 13b. The spinel is predominantly $\mathrm{MgAl}_{2} \mathrm{O}_{4}$ with small but varying contents of $\mathrm{FeO}$ (see the Mineral Chemistry section). Like the white material from MSNF \#46407/G, this object is similar in most respects to the fine-grained spinel-rich inclusions found in CV3 (ox) chondrites, the only differences again being grain size and thickness of the diopside rims on spinel.

Finally, grain \#123 (Fig. 14) is a large grain of icosahedrite (quasicrystalline $\mathrm{Cu}-\mathrm{Al}-\mathrm{Fe}$ metal) to which is attached yet another fine-grained aggregate of spinel, diopside, and olivine. This metal grain was the sample used for magnesium isotopic analysis (see below).

\section{Mineral Chemistry}

Average and representative analyses of olivine, pyroxene, and CAI spinel are tabulated in Table 1.

Figure 15a shows a large chondrule olivine crystal across which we made a WDS compositional profile (Fig. 15b), showing progressive zoning from essentially pure forsterite $\left(\mathrm{FO}_{100}\right)$ in the crystal core outward to $\mathrm{Fo}_{\sim 82}$ (the profile does not extend to the fayalitic rim). Calcium and aluminum decrease with increasing iron, whereas manganese correlates directly with iron. Similar minor element patterns are observed in chondrule olivines from the most unequilibrated chondrites, where they are interpreted as the result of primary igneous crystallization (see review by Brearley and Jones 1998). The calcium and aluminum contents of the core olivine might seem rather high (approximately $0.2-0.7 \% \mathrm{CaO}$ and approximately $0.05-0.25 \% \mathrm{Al}_{2} \mathrm{O}_{3}$ ), but, in fact, they are identical to data summarized by Brearley and Jones (1998) for CV3 chondrule olivines (see their fig. 46). The fayalitic olivine rims, and also the matrix olivine, are $\mathrm{FO}_{50-56}$ in composition (Fig. 15c), far more iron-rich than 

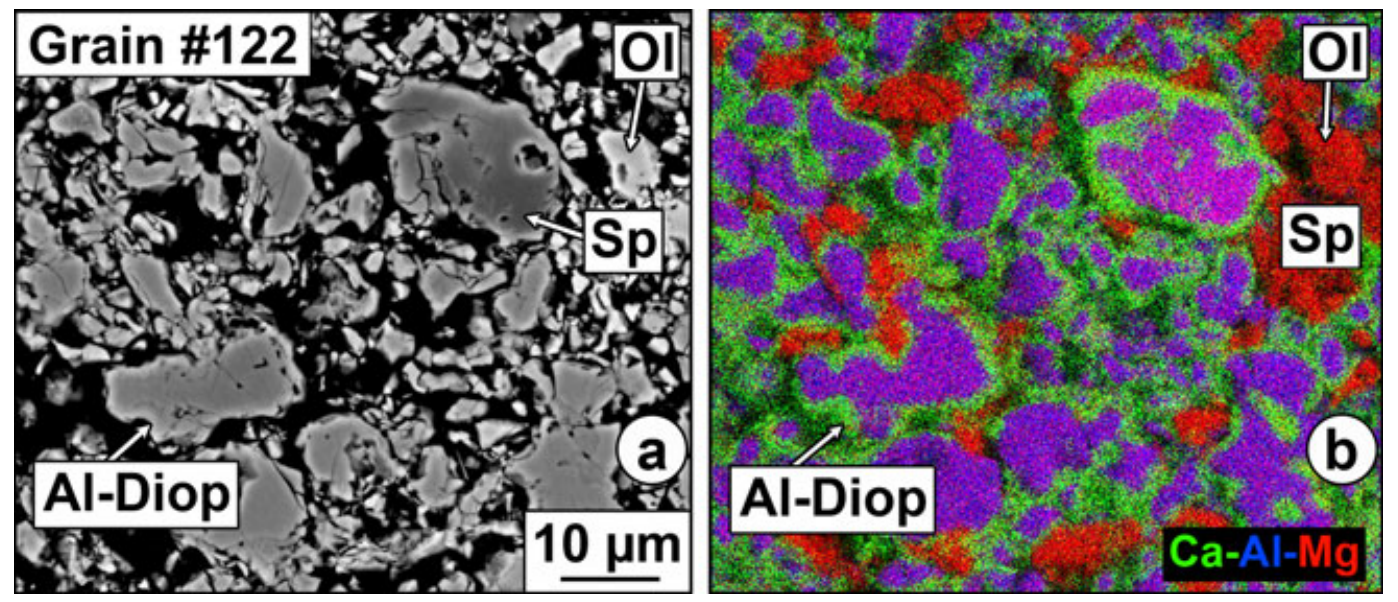

Fig. 13. Enlarged image of the interior of grain \#122. a) BSE image, showing irregular spinel (Sp) grains, olivine (Ol), and aluminous diopside (Al-Diop). b) Combined Ca-Al-Mg X-ray area map of the same region as in (a), showing more clearly the distribution of the minerals; note, in particular, that the pyroxene (green) everywhere occurs as rims around spinel (magenta), but does not rim the olivine (red).

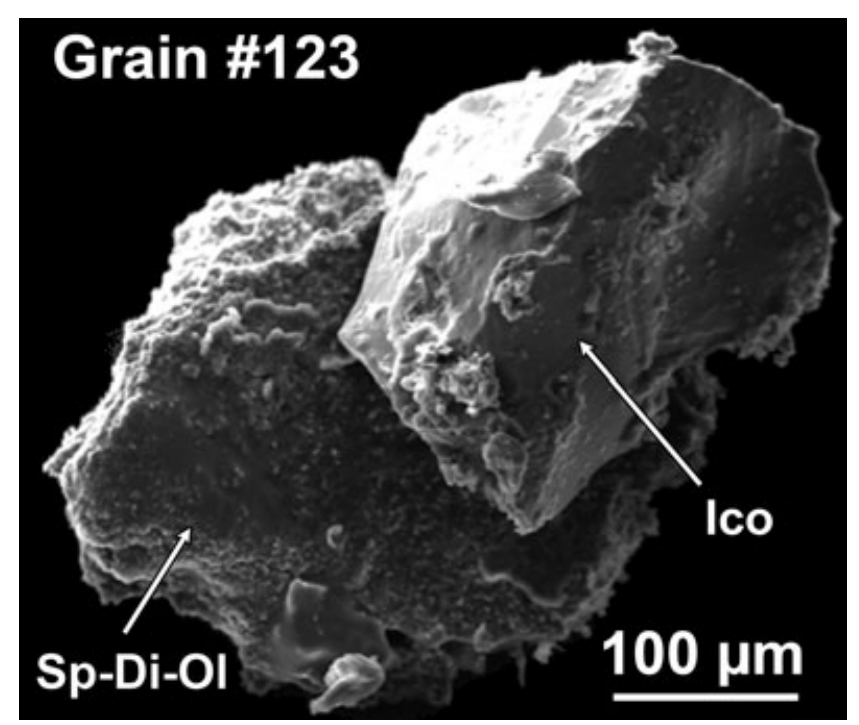

Fig. 14. a) Secondary electron image of grain \#123 sitting atop carbon sticky tape on an SEM mount. At right is an icosahedrite (Ico) grain, which was analyzed via SIMS for magnesium isotopic composition (see text). The metal is attached (at left) to a clump of spinel + diopside + olivine (Sp-Di-Ol)

the interior chondrule olivine. The composition range $\mathrm{Fo}_{50-56}$ is typical of ferroan olivine compositions in CV3 chondrite matrices (e.g., see Krot et al. 1995; their fig. 8). Figure 16 is a plot of $\mathrm{FeO}$ versus $\mathrm{MnO}$ in olivine from grains \#5 and \#121, showing a positive correlation that is typical of meteoritic olivine. Also shown for reference is the field of CV3 olivine (taken from Brearley and Jones 1998), which mostly overlaps our data, except at the high $\mathrm{FeO}-\mathrm{MnO}$ end. This compositional range is distinct from that observed in unequilibrated ordinary chondrites (e.g.,
Hewins and Zanda 2012), although broadly similar to that in other carbonaceous chondrites (Brearley and Jones 1998).

Pyroxene in the chondrules is enstatite $\left(\mathrm{Wo}_{1} \mathrm{En}_{98} \mathrm{Fs}_{1}\right)$; it shows no discernible compositional zoning of any kind.

The dominant sulfide is pentlandite with $13-23 \mathrm{wt} \% \mathrm{Ni}$. The iron-nickel metal is uniformly very nickel-rich (58$60 \mathrm{wt} \% \mathrm{Ni}$ ).

Spinel in the CAI fragment contains 3-15 wt $\%$ $\mathrm{FeO}$, substituting in as $\mathrm{FeAl}_{2} \mathrm{O}_{4}$. This compositional variation is typical of spinel in fine-grained CAIs from the oxidized-subgroup CV3 meteorites like Allende.

One metal grain, which was attached to the outside of grain \#5, was removed prior to preparation of the polished section, and analyzed by electron microprobe and by X-ray diffraction. The crystal structure has the characteristic five-fold symmetry of icosahedrite, and an average of five WDS analyses gives the composition $43.29 \% \mathrm{Al}, 38.54 \% \mathrm{Cu}$, and $18.17 \% \mathrm{Fe}$. This gives the structural formula as $\mathrm{Al}_{63} \mathrm{Cu}_{24} \mathrm{Fe}_{13}$, which is that of icosahedrite. EDS analyses of the grains present in the polished section of \#5 (see Fig. 8a) indicate that those grains also are icosahedrite.

\section{Oxygen Isotopic Compositions}

Oxygen isotopic compositions are plotted in Fig. 17. Forsteritic and ferroan olivine both plot on the carbonaceous chondrite anhydrous mineral (CCAM) line, below the terrestrial fractionation line. Diopside in the two CAIs (\#122, and the white rind on sample MSNF $46407 / G)$ is too fine-grained to analyze; however, the iron-rich hedenbergite in both is 
Table 1. Analyses ${ }^{\mathrm{a}}$ of chondrule olivine and pyroxene, matrix olivine, and calcium-aluminum-rich inclusion (CAI) spinel.

\begin{tabular}{|c|c|c|c|c|c|}
\hline & \multicolumn{3}{|l|}{ Average } & \multirow{2}{*}{$\frac{\text { Fe-poor }}{\text { CAI spinel }}$} & \multirow{2}{*}{$\frac{\text { Fe-rich }}{\text { CAI spinel }}$} \\
\hline & $\begin{array}{l}\text { Chondrule enstatite } \\
(n=2)\end{array}$ & $\begin{array}{l}\text { Chondrule olivine core } \\
(n=10)\end{array}$ & $\begin{array}{l}\text { Rim \& matrix olivine } \\
(n=5)\end{array}$ & & \\
\hline $\mathrm{SiO}_{2}$ & 58.21 & 41.94 & 35.13 & 0.21 & 0.00 \\
\hline $\mathrm{Al}_{2} \mathrm{O}_{3}$ & 0.82 & 0.24 & 0.14 & 69.00 & 65.96 \\
\hline $\mathrm{FeO}$ & 1.02 & 0.47 & 39.69 & 2.67 & 15.03 \\
\hline $\mathrm{MgO}$ & 39.74 & 56.50 & 24.16 & 26.49 & 18.39 \\
\hline $\mathrm{CaO}$ & 0.54 & 0.61 & 0.18 & 0.29 & 0.12 \\
\hline $\mathrm{TiO}_{2}$ & 0.16 & 0.08 & 0.05 & 0.02 & 0.11 \\
\hline $\mathrm{MnO}$ & 0.09 & 0.02 & 0.25 & 0.02 & 0.03 \\
\hline $\mathrm{NiO}$ & 0.31 & 0.11 & 0.14 & n.a. & n.a. \\
\hline Total & 100.90 & 99.97 & 99.74 & 98.71 & 99.65 \\
\hline & $\mathrm{Wo}_{1} \mathrm{En}_{98} \mathrm{Fs}_{1}$ & $\mathrm{Fo}_{99}$ & $\mathrm{Fo}_{52}$ & & \\
\hline
\end{tabular}

${ }^{\mathrm{a}}$ All analyses via WDS.

n.a., not analyzed
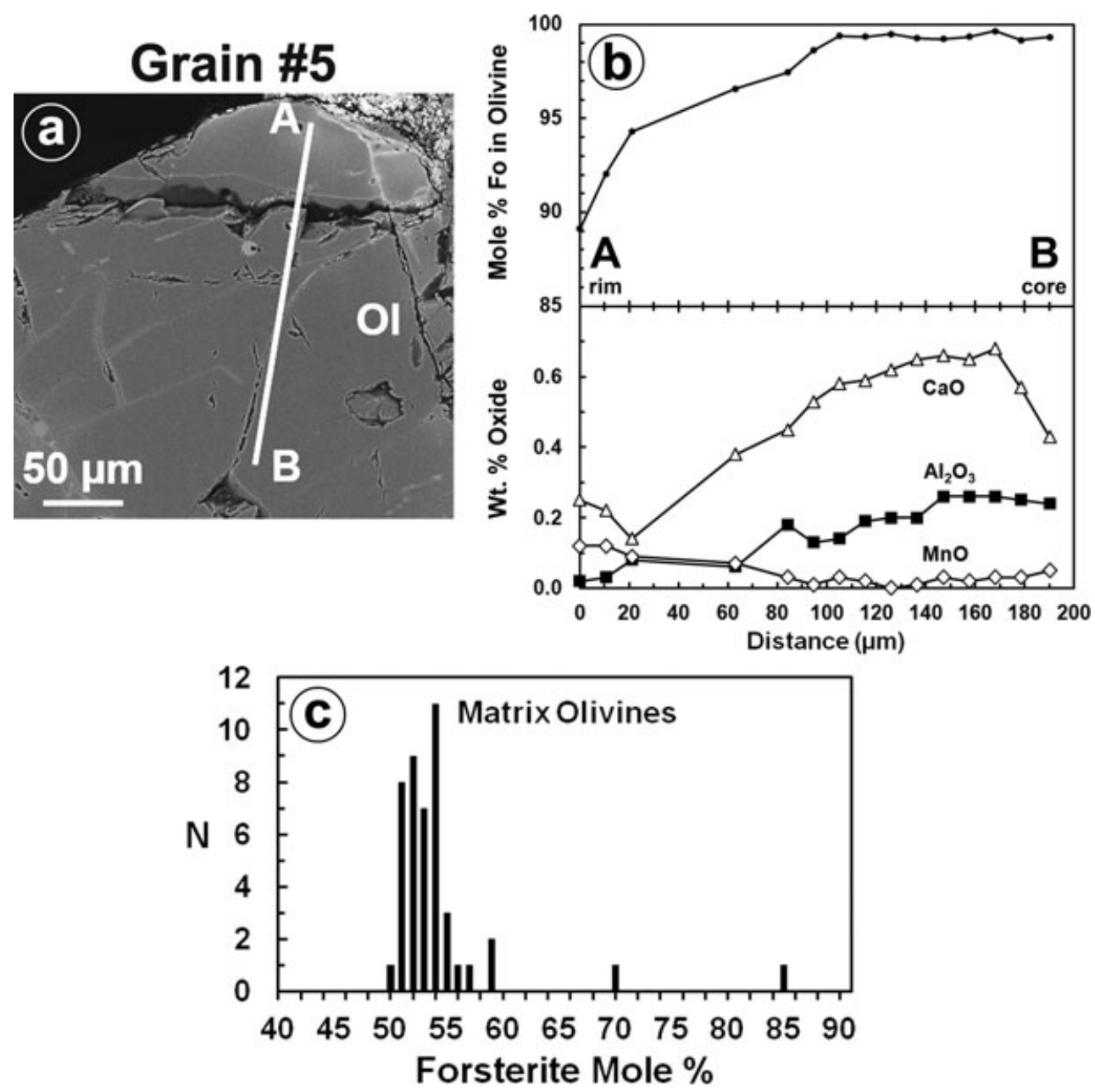

Fig. 15. a) Backscattered electron image of a large olivine crystal from a chondrule in grain \#5. The white line marked "A-B" is the location of the electron microprobe (WDS) compositional traverse shown in (b). c) Histogram of matrix olivine compositions in grains \#5 and \#121. The few relatively magnesian compositions (Fo $>58)$ are all from the interiors of larger grains. All data used for the histogram are EDS analyses. 


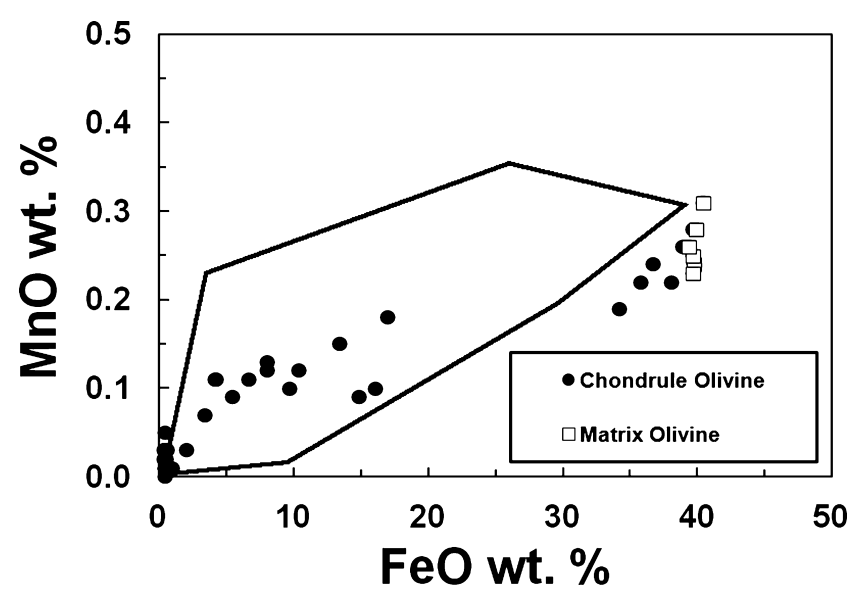

Fig. 16. $\mathrm{FeO}$ versus $\mathrm{MnO}$ (wt\% oxide) in olivine from grains $\# 5$ and \#121. The outlined area represents the field of olivine from CV3 chondrites, as summarized in Brearley and Jones (1998) and references therein.

${ }^{16} \mathrm{O}^{-}$depleted, consistent with iron-rich pyroxenes analyzed in CAIs from CV3 chondrites (e.g., Cosarinsky et al. 2003). Spinel in grains \#122 and MSNF 46407/G is ${ }^{16} \mathrm{O}$-rich, at $\delta^{17} \mathrm{O}$ approximately $-40-48 \%$, typical of spinel from CAIs in carbonaceous chondrites.

\section{Magnesium Isotopic Compositions}

The magnesium isotopic compositions of $\mathrm{Cu}-\mathrm{Al}-\mathrm{Fe}$ metal in grain \#123 are plotted in Fig. 18. No excess ${ }^{26} \mathrm{Mg}$ was detected even at ${ }^{27} \mathrm{Al} /{ }^{24} \mathrm{Mg}$ ratios of approximately 1200 , and thus there is no evidence for the in situ decay of ${ }^{26} \mathrm{Al}$.

\section{${ }^{14} \mathrm{C}$ Ages of the Host Clay Layer}

Table 2 gives carbon isotopic data for the three analyzed fractions of the blue clay layer from which some of the meteorite grains were extracted. The $<400{ }^{\circ} \mathrm{C}$ fraction places a lower limit on the age of the clay, and the $>400{ }^{\circ} \mathrm{C}$ fraction is an upper limit (e.g., McGeehin et al. 2001). The charcoal ought in principle to give the actual age of deposition, but because the charcoal is disseminated and fine-grained it could be reworked to some degree or blown in from multiple

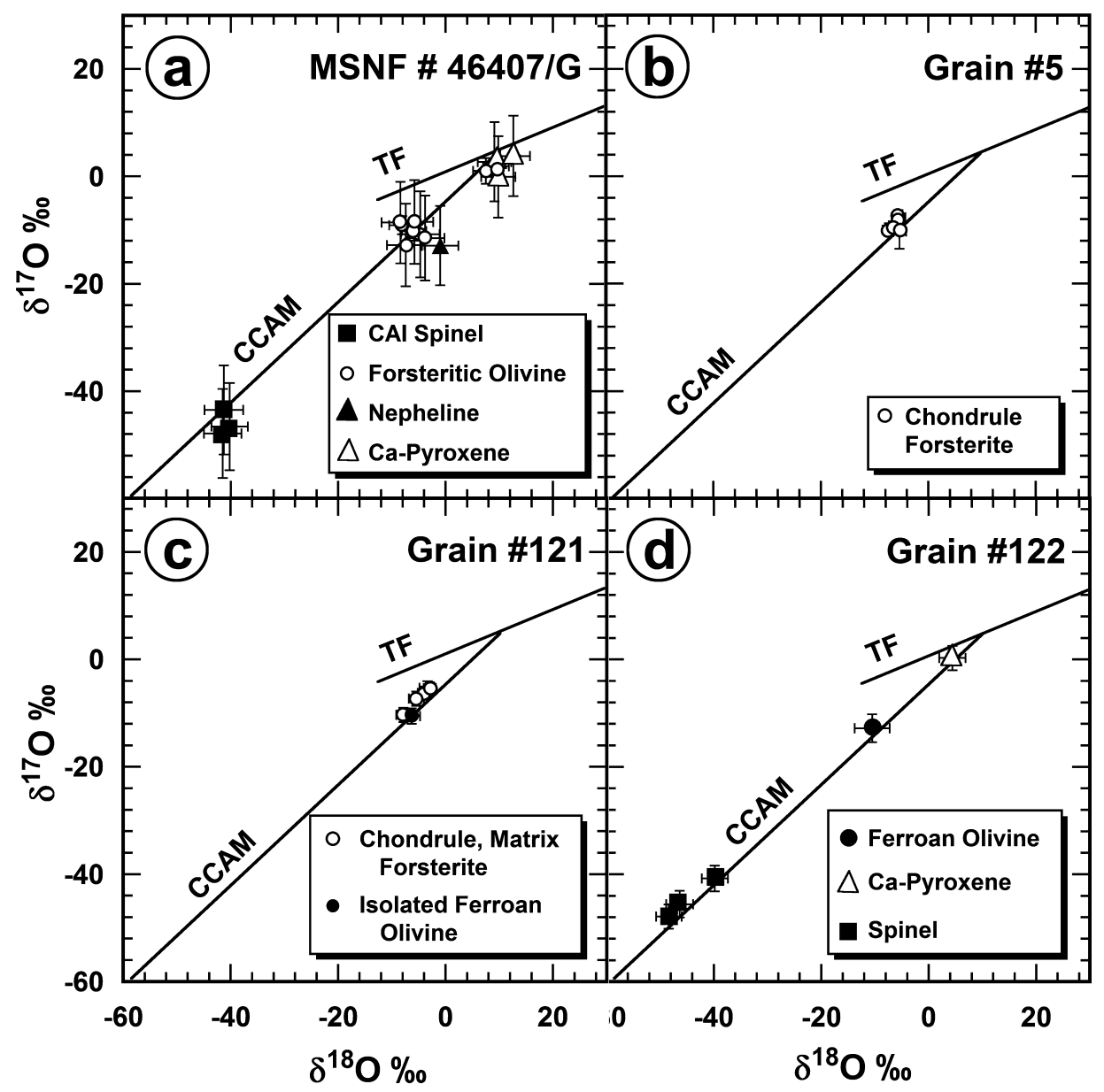

Fig. 17. Oxygen isotopic composition of grains from the Khatyrka meteorite. 


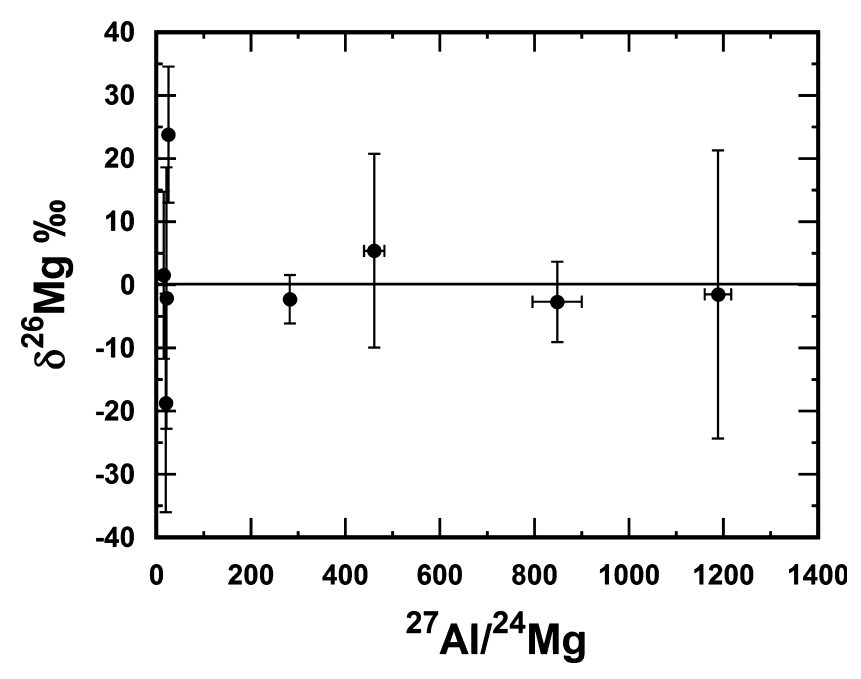

Fig. 18. Magnesium isotopic composition of icosahedrite from the Khatyrka meteorite.

Table 2. Radiocarbon ages of clay and charcoal.

\begin{tabular}{lclcc}
\hline Material & $\delta^{13} \mathrm{C}(\%)$ & $\pm 2 \sigma$ & ${ }^{14} \mathrm{C}$ age yr \\
before present & $\pm 1 \sigma$ \\
\hline Charcoal & -26.1 & $0.05 \%$ & 8004 & 55 \\
Fine clay $\left(>400{ }^{\circ} \mathrm{C}\right)$ & -24.4 & $0.05 \%$ & 12533 & 73 \\
Fine clay $\left(<400{ }^{\circ} \mathrm{C}\right)$ & -25.2 & $0.05 \%$ & 6670 & 50 \\
\hline
\end{tabular}

sources. In our case, the age of the charcoal $(8004 \pm 55$ ${ }^{14} \mathrm{C}$ yr BP $(1 \sigma)$ and the age of the $<400{ }^{\circ} \mathrm{C}$ fraction $(6670 \pm 50){ }^{14} \mathrm{C}$ yr BP $(1 \sigma)$ are within about 1000 years of each other, and the age of the $>400{ }^{\circ} \mathrm{C}$ fraction $(12533 \pm 73){ }^{14} \mathrm{C}$ yr BP $(1 \sigma)$ is significantly older as expected. We conclude that the likely age of deposition of the blue clay is in the range $6670-8004{ }^{14} \mathrm{C}$ yr BP, as defined by the charcoal age and the $<400{ }^{\circ} \mathrm{C}$ fraction. This represents the minimum age for the arrival of the meteorite on Earth.

\section{DISCUSSION}

\section{Khatyrka and its Unique Metal Alloys}

The association of the Khatyrka meteorite with the remarkable $\mathrm{Cu}-\mathrm{Al}-\mathrm{Fe}$ metal alloys is the reason why this particular tiny meteorite is so special. Thus, it is necessary to establish here that the metal is indeed an integral part of the meteorite. Moreover, the reader may be skeptical that any alloy containing metallic aluminum can even be natural, much less extraterrestrial. We address these questions here.

The question of whether the metal is natural or else some man-made artifact is answered by two kinds of evidence. The first is that the metal-bearing grains were extracted by us in 2011 from $>6700$ year old clay layers.
The ability to make any kind of aluminum-bearing metallic alloy did not exist even $200 \mathrm{yr}$ ago, much less $6700 \mathrm{yr}$ ago. The second point is that in the original sample in which natural icosahedrite was identified, MSNF \#46407/G from the collection in Florence, the metal is intimately intergrown with silicates and those silicates are unambiguously extraterrestrial based on their oxygen isotope compositions (Bindi et al. 2012). Although not intergrown with silicates in grains \#5, $\# 121, \# 122$, and \#123, Cu-Al metal particles clearly are attached to those grains. Thus, there can be no doubt that the $\mathrm{Cu}-\mathrm{Al}$ metal alloys are natural and, at least for those cases where there are silicates and oxides to analyze via ion microprobe, they demonstrably are also extraterrestrial.

There are complications, however. One is the fact that the recovered grains are so diverse in character. Grains \#5 and \#121 are fragments of an oxidized CV3 chondrite. Grains \#122 and \#123 are fine-grained spinelrich CAIs that are identical to those in oxidized CV3 chondrites, each having attached icosahedrite metal particles (e.g., Fig. 14). The Florence sample (MSNF $\# 46407 / \mathrm{G}$ ) is a unique achondritic intergrowth of metal and silicates. Two samples consist of $\mathrm{Cu}-\mathrm{Al}$ metal only. Oxygen isotopes tie together only those grains that contain silicates and oxides, but what ties all of the grains together is the presence of the $\mathrm{Cu}-\mathrm{Al}$ alloys. If we assume that all of the $\mathrm{Cu}-\mathrm{Al}$ alloys have a common origin, then the simplest interpretation is that the metal particles and metal-achondrite intergrowths are an exotic component that were accreted along with chondrules and CAIs into an otherwise-normal oxidized CV3 chondrite.

A second complication is the way the metal occurs in the chondritic grains $(\# 5, \# 121, \# 122, \# 123)$. In all four cases, the original grains (prior to making polished sections) had metal particles firmly attached to their exterior surfaces (Fig. 7). But in no cases did the polished sections reveal a metal particle enclosed within meteorite matrix. Grain \#121 had a tiny cupalite grain enclosed within a chondrule (Figs. 9 and 10c). The section of grain \#5 (Fig. 8a) has eight exposed $\mathrm{Cu}-\mathrm{Al}$ particles, all of which are on the outer surface or inside a large internal "cavity" that almost certainly is simply a re-entrant of the outer surface from the third dimension. Also disconcerting is that these same grains are all separated from the meteorite fragment by several micrometers of epoxy, even though they were firmly attached prior to sectioning. The reason for this gap, thermally induced differential movement during the epoxy curing process, also suggests a possible explanation for the occurrence of the metal particles on outer surfaces. We think that over time within the original clay layer, repeated expansion and contraction 
of the metal particles relative to the meteoric silicates led to creation of internal fractures. Breakage along these fractures naturally meant that the metal ended up being sited on the surfaces of those breaks. We recognize that this idea is somewhat ad hoc, and we intend to continue to search for more definitive evidence. Most of the masses of grains \#5 and \#121 remain untouched within their epoxy mounts, and we ultimately will use a combination of CT-scanning plus focused ion-beam (FIB) extraction to search for an internal contact. This is beyond the scope of the current manuscript, however.

The origin of the remarkable and (so far) unique $\mathrm{Cu}-\mathrm{Al}-\mathrm{Fe}$ alloy grains is not the subject of this paper, but it certainly is the subject of our ongoing research and it does merit some comment here. We have established that the metal is extraterrestrial in origin, and it is associated not just with a meteorite, but in some cases with CAI fragments. Moreover, we (Bindi et al. 2012) already showed that the reducing conditions required to form such alloys are (perhaps coincidentally) approximately those of the inner solar nebula gas in which $\mathrm{Ti}^{3+}$-bearing CAIs formed (e.g., Grossman et al. 2008). Therefore, it was natural to question whether the metal might actually be an unusual primitive nebula product. It was for this reason that we searched for, but did not find, evidence of extinct ${ }^{26} \mathrm{Al}$. All we can say at this point is that the metal formed at least 2-3 million years subsequent to CAIs with ${ }^{26} \mathrm{Al} /{ }^{27} \mathrm{Al}=\sim 5 \times 10^{-5}$, given the usual assumption of approximately homogeneous distribution of ${ }^{26} \mathrm{Al}$ throughout the inner solar system at the time of solar system formation. An equally perplexing mystery that we are actively investigating is the association of aluminum with copper, two metals with profoundly differing cosmochemical properties.

\section{Meteorite Classification}

Apart from their unusual metal, Khatyrka grains such as \#5, \#121, and \#122 are primarily CV3 (ox) chondrites. The distinctive matrix texture of \#5 and \#121 with the "barrel-shaped" (platy) olivines having a narrow compositional range of $\mathrm{FO}_{50-56}$; the equally distinctive mantling of primary forsteritic olivine with sharp overgrowths of ferroan olivine; and the finegrained spinel-rich CAIs (e.g., \#122) with secondary hedenbergite, nepheline, and sodalite are all typical features of CV3 (ox) chondrites. However, the overall classification of Khatyrka is somewhat complicated by the presence of the $\mathrm{Cu}-\mathrm{Al}$ metal \pm silicate assemblages. The metal and metal-bearing clasts appear to be accretionary components of the chondrite rather than being postaccretion in origin. In this sense, the paradox of having the extremely reduced metallic assemblage in association with the rather oxidized chondrite is no different (except in degree) than the similar occurrence of trivalent-titanium bearing CAIs in the same meteorite. If all of the metal and metal + silicate particles are truly some unusual kind of achondrite clast as originally represented by the Florence grain (MSNF $\# 46407 / \mathrm{G})$, then Khatyrka is a complex chondritic breccia whose host lithology is CV3 (ox). Even the CV3 (ox) lithology is unusual in some ways, for example, by the apparent absence of magnetite and the unusual sulfide-metal-phosphate nodules. If the absence of magnetite is real and not a sampling issue, this could indicate that the secondary alteration of Khatyrka occurred under somewhat more reducing conditions than in the case of Allende and other oxidized CV3s, and in the presence of a fluid with somewhat lower $\mathrm{Fe} / \mathrm{Ca}$ (relative to Allende), such that calcium-iron silicates were stabilized relative to magnetite (see Krot et al. 1998a).

The shock stage is as-yet unknown. As stated earlier, all specimens are in the form of thick polished sections, so none of the relevant optical properties could be determined.

The individual fragments show few signs of terrestrial weathering (rare hematite, but not present in the samples described herein), although they occur in a sedimentary deposit. Based strictly on the scale proposed by Wlotzka (1993), Khatyrka would have a weathering grade of $\mathrm{W} 0$, because there is no iron oxide around the metal grains in any of the fragments described herein. The fact that the $\mathrm{CuAl}$ alloy grains are also unweathered supports a W0 grade. We emphasize, however, that such small grains are unlikely to be representative of the meteorite as a whole.

Acknowledgments - The expedition to Chukotka was supported by a grant from an anonymous donor to Princeton University (PJS, Principal Investigator). The research was supported, in part, by the NSF MRSEC program through New York University (grant DMR0820341; PJS); the MIUR, PRIN 2009 project "Modularity, microstructures and non-stoichiometry in minerals" (LB); and the Chairman's Discretionary Fund, Dept. of Mineral Sciences, SI (GJM). We have benefitted from comments and many contributions to detailed imaging studies of the samples by N. Yao. The expedition was enabled by a co-operative agreement between Princeton University and the Institute of Geology of Ore Deposits, Mineralogy, Petrography and Geochemistry (IGEM) of the Russian Academy of Science (RAS). The expedition also hugely benefitted from the logistical aid provided by Olga Komelkova, Victor Komelkov, and Bogdan Makovskii, all from 
Anadyr, who organized and provided all transportation and provisions both in base camp in the Koryak Mountains and en route between the base camp and Anadyr. We also are grateful to Prof. A. J. T. Jull, George Burr, and the rest of the team at the Accelerator Mass Spectrometry Laboratory, University of Arizona, for their excellent work in producing the ${ }^{14} \mathrm{C}$ age dates of the blue clay layer. Finally, this manuscript benefitted greatly from constructive reviews by Drs. Michael Weisberg, Misha Petaev, and Associate Editor Adrian Brearley.

\section{Editorial Handling - Dr. Adrian Brearley}

\section{REFERENCES}

Bindi L., Steinhardt P. J., Yao N., and Lu P. J. 2009. Natural quasicrystals. Science 324:1306-1309.

Bindi L., Steinhardt P. J., Yao N., and Lu P. J. 2011. Icosahedrite, $\mathrm{Al}_{63} \mathrm{Cu}_{24} \mathrm{Fe}_{13}$, the first natural quasicrystal. American Mineralogist 96:928-931.

Bindi L., Eiler J. M., Guan Y., Hollister L. S., MacPherson G. J., Steinhardt P. J., and Yao N. 2012. Evidence for the extra-terrestrial origin of a natural quasicrystal. Proceedings of the National Academy of Sciences 109:1396-1401.

Brearley A. J. and Jones R. H. 1998. Chondritic meteorites. In Planetary materials, edited by Papike J. J. Reviews in mineralogy and geochemistry, vol. 36. Washington, D.C.: Mineralogical Society of America. pp. 3-01-3-398.

Burr G. S. and Jull A. J. T. 2010. Accelerator mass spectrometry for radiocarbon research. In The encyclopedia of mass spectrometry volume 5, elemental and isotope ratio mass spectrometry, edited by Beauchemin D. and Matthews D. E. (volume editors); Gross M. L. and Caprioli R. M. (series editors). Amsterdam: Elsevier. pp. 656-669.

Cosarinsky M., Leshin L. A., MacPherson G. J., Krot A. N., and Guan Y. 2003. Oxygen isotopic composition of CaFe-rich silicates in and around an Allende Ca-Al-rich inclusion (abstract \#1043). 34th Lunar and Planetary Science Conference. CD-ROM.

Donahue D. J., Linick T. W., and Jull A. J. T. 1990. Isotoperatio and background corrections for accelerator mass spectrometry radiocarbon measurements. Radiocarbon 32:135-142.

Grossman L., Beckett J. R., Fedkin A. V., Simon S. B., and Ciesla F. J. 2008. Redox conditions in the solar nebula: Observational, experimental, and theoretical constraints. In Oxygen in the solar system, edited by MacPherson G., Middlefeldht D. and Jones J. Reviews in Mineralogy and Geochemistry, vol. 68. pp. 93-140.

Gualtieri L., Glushkova O., and Brigham-Grette J. 2000. Evidence for restricted ice extent during the last glacial maximum in the Koryak Mountains of Chukotka, far eastern Russia. Geological Society of America Bulletin 112:1106-1118.
Hewins R. H. and Zanda B. 2012. Chondrules: Precursors and interactions with the nebular gas. Meteoritics \& Planetary Science 47:1120-1138.

Krot A. N., Scott E. R. D., and Zolensky M. E. 1995. Mineralogical and chemical modification of components in CV3 chondrites: Nebular or asteroidal processing? Meteoritics 30:748-775.

Krot A. N., Petaev M. I., Zolensky M. E., Keil K., Scott E. R. D., and Nakamura K. 1998a. Secondary calcium-iron minerals in the Bali-like and Allende-like oxidized CV3 chondrites and Allende dark inclusions. Meteoritics 33:623-645.

Krot A. N., Petaev M. I., Scott E. R. D., Choi B.-G., Zolensky M. E., and Keil K. 1998b. Progressive alteration in CV3 chondrites: More evidence for asteroidal alteration. Meteoritics 33:1065-1085.

Levine D. and Steinhardt P. J. 1984. Quasicrystals: A new class of ordered structures. Physical Review Letters 53:2477-2480.

Lu P. J., Deffeyes K., Steinhardt P. J., and Yao N. 2001. Identifying and indexing icosahedral quasicrystals from powder diffraction patterns. Physical Review Letters 87:275507.

McGeehin J., Burr G. S., Jull A. J. T., Reines D., Gosse J., Davis P. T., Muhs D., and Southon J. 2001. Steppedcombustion ${ }^{14} \mathrm{C}$ dating of sediment. Radiocarbon 43:255262.

Peck J. A. and Wood J. A. 1987. The origin of ferrous zoning in Allende chondrule olivines. Geochimica et Cosmochimica Acta 51:1503-1510.

Razin L. V., Rudashevskij N. S., and Vyalsov L. N. 1985. New natural intermetallic compounds of aluminum, copper and zin-khatyrkite $\mathrm{CuAl}_{2}$, cupalite $\mathrm{CuAl}$ and zinc aluminides from hyperbasites of dunite-harzburgite formation. Zapiski Vsesoyuznogo Mineralogicheskogo Obshchestva 114:90-100. (In Russian)

Shechtman D., Blech I., Gratias D., and Cahn J. 1984. Metallic phase with long-range orientational order and no translational symmetry. Physical Review Letters 53:19511954.

Schrader D. L. and Lauretta D. S. 2010. High-temperature experimental analogs of primitive meteoritic metal-sulfideoxide assemblages. Geochimica et Cosmochimica Acta 74:1719-1733.

State Geological map of Russian Federation1: 50000, III10-49,50. 1976. Anadyr Geological-Prospecting Expedition.

Stavsky A. P., Chekhovich V. D., Kononov M. V., and Zonenshain L. P. 1990. Plate tectonics and palinspastic reconstructions of the Anadyr-Koryak region, northeast USSR. Tectonics 9:81-101.

Stuiver M. and Polach H. 1977. Reporting of ${ }^{14} \mathrm{C}$ data. Radiocarbon 19:355-363.

Weinbruch S., Palme H., Müller W. F., and El Goresy A. 1990. FeO-rich rims and veins in Allende forsterite: Evidence for high temperature condensation at oxidizing conditions. Meteoritics 25:115-125.

Wlotzka F. 1993. A weathering scale for the ordinary chondrites. Meteoritics 28:460. 